\title{
The Impact of Collaboration on the Process-Based Writing in EFL Classrooms in Saudi Arabia
}

\author{
Badia Hakim ${ }^{1}$ \\ ${ }^{1}$ King Abdulaziz University, Jeddah, Kingdom of Saudi Arabia \\ Correspondence: Badia Hakim, King Abdulaziz University, Jeddah, Kingdom of Saudi Arabia. E-mail: \\ badiahakim82@gmail.com
}

Received: July 16, 2018 Accepted: August 10, 2018 Online Published: August 22, 2018

doi:10.5539/ijel.v8n6p164 URL: https://doi.org/10.5539/ijel.v8n6p164

\begin{abstract}
This research is a study of the impact of collaboration on the process-based writing in EFL classrooms in Saudi Arabia. It focuses on methods that contribute to the enhancement of productivity in writing. First, a definition of the term "collaboration" in the process-based EFL writing is presented and then, the advantages of collaborative process-based writing are discussed in further detail. The research mainly focuses on the practical aspects of introducing the building blocks and the procedural aspects of collaborative process-based writing into classrooms in Saudi Arabia. The main goal is to contribute to an overall understanding of collaborative process-based writing. In this context, the instructor tries to help students get further involved in collaborative and dialog-based activities through the process of writing. Another chief goal of introducing this technique is to help students produce better academic writing pieces and improve their writing skills as they move in their writing process from pre-writing to post-writing.
\end{abstract}

Keywords: process-based writing, collaboration, the EFL classroom

\section{Introduction}

Collaborative learning is widely applied in language classrooms. As defined by Lai (2011), "collaborative learning, is commonly considered as a combined academic effort by individuals or members of a group or students and an instructor." It is regarded as the joint effort of group members to accomplish a particular learning task in a coordinated activity. Working in groups is generally considered the main writing strategy in collaborative learning. In this strategy, students work in small groups of two or three people. They work together to share knowledge and language resources and exchange views with others towards creating a combined writing item. In other words, collaborative learning involves knowledge and linguistic resource sharing, mutual engagement, negotiation, and a jointly completed product. Different experimental studies have discussed the pros and cons and the efficiency of the collaborative learning process (e.g. the patterns of group work activities and the series of collaborative dialogues) in ESL/EFL classrooms (Sert, 2005; Storch, 2011; Wanatabe \& Swain, 2007). In Saudi Arabia, little emphasis has been put on the integration of collaboration into process-based writing instruction, especially in the EFL context. Aiming to overcome this shortcoming, the current study has focused on an evaluation of the integration of collaboration into process-based EFL writing classrooms where writing is considered as a process and as a productive skill.

The current study was structured, conducted, and presented in three main parts: (1) the operative definition of collaboration in the process-based EFL writing classroom, (2) the advantages of process-based EFL writing instruction, and (3) step-by-step procedures for process-based EFL writing instruction. In general, the aim of this study is to develop a practical approach to the effective application of collaboration in all aspects of the EFL writing process in Saudi Arabian students.

\subsection{Introducing the Concept of Collaboration in Process-Based EFL Writing Classrooms}

According to Jacobs (2006), collaborative work can be described as a series of pair or group work. The incorporation of collaboration in a process-based writing activity means having two or more students work on a given writing task or topic together. In this writing process, they are supported and guided by the teacher to collaborate and produce an item. This type of collaboration is a joint venture in which students, through their combined effort, produce one writing text (Storch, 2005). The concept of the production of a joint text by two or 
more student writers provides a basis for "the joint ownership of the document produced by them" (Storch, 2011). It helps students overcome their weaknesses in the writing process and, through discussions and sharing ideas, produce a strong and relatively error-free text. When introducing a collaborative approach into the process-based writing classroom, teachers need to take a few issues, discussed briefly in the following, into consideration.

The most important aspect of the process-based writing is the arrangement of right groups for students. Forming groups and producing the right combination of students in these groups is the most important factor and the teacher needs to negotiate with students on this. Forming small groups of two or three students is the preferred and ideal arrangement that allows for greater participation and better productivity (Jacobs, 2006). There are invariably two scenarios for group formation: teacher-selected groups and student-selected groups (Widodo, 2006). The former is, of course, based on the teacher's choice and vision. It is important to include students of mixed ability levels in the groups (e.g. a low achiever and a high achiever working together). It is also imperative to include students from different intellectual levels to have equal participation in the writing process in a mixed-ability group. Groups formed by students are, on the other hand, completely based on their selection criteria for the productive work. In this scenario, the teacher delegates the whole task of selecting group members to students and gives them freedom so as to feel comfortable and work together efficiently. In both cases, it is imperative to understand that the level of participation in the production of a collaborative writing text is not compromised.

It is also necessary to ensure that there is complete collaboration in the process-based writing classroom and students work collaboratively throughout the entire process of writing (from the pre-writing to post-writing stages). It is also important that this process of writing is completed by the same group members. Teachers should make sure that groups with the same members complete one assigned writing process cycle and the same groups with the same members are assigned another particular piece of writing until one writing process cycle is completed. So as to let their students benefit from peers, teachers can shuffle them for another writing process cycle. According to Nelson and Murphy (1992), periodic shifting and rotation of members of groups provide an opportunity for the students to learn from each other through periodic interaction with different readers and writers.

The criteria for member rotation in groups can be formulated around the factors below:

(1) The preference of students based on their compatibility;

(2) (1) The preference of students based on their skill and proficiency level in language and writing;

(3) (1) The preference of students based on their interest in the selected topics.

\subsection{The Advantages of Collaboration in the Process-Based Writing Classroom}

There are certain advantages to collaboration in the process-based writing. It provides students with an opportunity to work with their ideas collectively and in a way that is completely different from the individual writing process. Sharing ideas and cooperation encourages social interaction and enhances the sense of reciprocal ownership in students. It also trains students in quick decision-making on the major components of the writing process including the content, the structure, and the language items (Storch, 2005).

Furthermore, in the process of preparing a draft for a given writing task, students get equal opportunities to share knowledge and language resources. Sharing linguistic resources helps students take responsibility for the completion of a particular writing task. The outcome of this collaborative writing process is the improvement of students' abilities and skills on a shared basis. In contrast to the individual writing process, a collaborative writing process provides students with an opportunity for specific interactive consultations with the aim of turning them into notions with unified and comprehensible writing samples without any need for a feedback session with peers and/or teachers. As a result, in the collaborative writing process, there is always vigorous involvement of more students through peer feedback or response sessions implemented in pairs or groups. By having well-managed peer feedback sessions with intense training on the peer feedback process, students are able to receive more constructive, informed, and supportive feedback from their peers.

Another advantage of the collaborative process is that it enables students to organize writing activities as they work together while formulating an assigned essay (Widodo, 2006). As Harmer (2007) states, it also helps build a comprehension environment of shared accountability for the completion of a specific writing task, thus assisting students in achieving collective pride in their collaborative work. In addition, the incorporation of collaboration into the process-based writing boosts social interaction, which in turn results in the promotion of an atmosphere in which low achieving students receive assistance from their high achieving peers and improve their 
grades. A major learning point for the low achieving students could be learning the use of different writing strategies by high achieving students, which helps the former to acquire better writing skills. The idea of collective scaffolding, presented by Donato (1994), can be studied in the same context. He believes that collaborative process-based writing encourages high achieving students to have an awareness of their social obligation to a framework of support for others, so they develop a structure of helpful ideas for each other while writing completed essays through collaboration.

Last but not least, a further important advantage of collaborative process-based writing is that students learn to build, enhance, and develop their critical thinking skills. When students write within such a process, they get an opportunity to collaboratively evaluate the strengths and weaknesses of the produced drafts. It is often difficult for students to routinely evaluate the quality of drafts critically, but this turns easier and more practical through a step - by - step process through which they learn how to evaluate the quality of their drafts and critique the writing product of their peers (Nelson \& Murphy, 1992). As Stapleton (2001) states, critical thinking can be enhanced through the comprehension of the presented content and schematics (prior knowledge) as these two fundamental components help shape the variety and complexity of the argumentation process. For instance, if students were familiar with the content understanding process, they would have a better opportunity to refine their notions and present constructive critical feedback on the writing product produced by their peers. By getting involved in a step by step process of writing and teacher support framework (e.g. enabling students to evaluate and analyze a piece of writing), they will be trained to become engaged writers. They can acquire skills in amplification, description, and shielding of their opinions with the help of each other. This process results in the promotion of social interaction and exchange of ideas through group discussions and, in turn, leads to the fulfillment of intended ideas and notions.

Finally, the incorporation of collaboration into process-based writing can help create a sympathetic learning environment for students and provide them with an opportunity to experience the process of writing collaboratively. A collaborative writing process helps reduce stress in the classroom atmosphere (Gaith, 2002).

\section{Implementation of Collaborative Process-Based Writing}

\subsection{Introduction of the Pre-writing Activity}

\subsubsection{Group Formation}

Group formation is the most important step in the implementation of collaboration in the process-based writing. As discussed earlier, the process of group formation depends on either the teachers or students' choice, the ability of students with varying proficiency levels in language and writing, or on their interest in different writing topics. Furthermore, a teacher ought to encourage students to form groups so as to enable them to come together through mutual agreement and interaction between the teacher and students or between the individual members of each group.

\subsubsection{Teacher Support Framework}

Providing support to students to complete their writing tasks is the main idea behind the teacher support framework. The teacher's role remains as that of a facilitator who tries to help students by making the writing task simpler and easier and turning the situation supportive for students so that they complete the task (Hammond, 2002).

Interestingly, there is a long list of various types of scaffolding or support systems provided by teachers to students for doing solo writing or collaborative process-based writing. The main components of a support system include:

a. writing prompts - e.g. simple clue statements, writing in response to questions, or descriptions of pictures that are a source of informational input for students;

b. perceiving activities - e.g. investigating the features of an essay;

c. using text coordinated construction for writing a model essay;

d. sorting literary information in academic writing - e.g. raising students' awareness of how to deal with plagiarism and learn to use sources in the right way and appropriately.

Through the appropriate use of the teacher support system in the process of writing, teachers can help students complete their writing tasks more easily and efficiently (e.g. generate innovative ideas in the drafting process and while giving feedbacks and comments on other students' drafts). 


\subsubsection{Creating Collaborative Ideas}

Rao (2007) offers a practical method to provide students with an opportunity to activate their prior knowledge of a specific topic before starting to write. This helps them gather further material and related information they need to produce a good writing item. One main reason is also to help students generate innovative ideas for their drafts. There are techniques that can be helpful in this brainstorming process. While working in groups, students should be given free rein to express any innovative ideas that are in their mind and share these ideas with one another. Commonly used brainstorming techniques are clustering, listing, outlining, and free writing. Once students acquire these skills, they are able to select a topic of their interest, learn the skills to formulate a topic that suits their assigned writing task, and gather the required amount of information needed to develop their ideas. As Rao (2007) states, at this phase, students get an opportunity to arrange their thinking process, be more innovative, and work collaboratively, and organize their ideas in a clear way.

\subsection{The Process of Creating the Body of Writing}

\subsubsection{Drafting with Collaboration}

At this stage, once students formulate their clear outline ideas, they move forward to a drafting activity. In drafting, teachers can choose one of the following for students: they can either work collaboratively to produce a handwritten piece of writing or they can direct students on how to use a computer and produce a type-written sample. The use of a computer to produce a type-written sample, of course, depends on the availability of a computer, in the first place, and after making sure that students are familiar with software such as the Microsoft Word. How efficiently students are guided in the production of either a handwritten or a type-written sample using available instructional resources (e.g. computers) is of course largely dependent on the teacher. Students should also have a role in the selection of the writing mode (i.e. the production of a handwritten or a type-written sample using a word processor). Besides the selection of the mode of writing, teachers should guide students in the collaborative writing process by working with them, sharing ideas, and, ultimately, creating a text till one writing process cycle is completed.

Another similarity between solo drafting and collaborative drafting in writing is that in both, language accuracy is not considered the main focus and the goal is just to help students develop their ideas to produce a rough draft. It also goes on to confirm the fact that rough drafts should not be expected to be perfectly written outputs in the process-based writing. Collaboration in process-based writing, on the contrary, means looking for new ideas, promoting eloquence, and refining ideas so as to enable students to produce a written piece. In producing their drafts, students practice various writing techniques in order to express their ideas collaboratively. A common practice among Saudi Arabian students is that they present and elaborate their ideas in Arabic and then translate them into English. Keeping this in mind, the teacher should give students enough time in the completion of their drafts. In addition, in the drafting phase, teachers ought to help students to complete their writing by producing multiple drafts. Producing the first, the second, the third, and/or the fourth drafts using the teacher and the peers' feedback should be encouraged. There are certain factors that are directly related to the total number of drafts produced by students including the type of group or pair, the maximum time allotted for the completion of the writing task, and the proficiency level of students in the language and in writing. One of the biggest advantages of incorporating collaboration into process-based writing is that, while merging their new ideas into completed drafts, students get an opportunity to share exceptional resources like language and content.

\subsubsection{Feedback Strategy in Collaboration}

Giving constructive feedback is the key to developing students' writing skills. This feedback can come from teachers or peers. In giving feedback, some points should be taken into account such as the notions or ideas for the content, the linguistic organization, and the form and structure including word expressions and grammar. Having a harmonious blend of all these factors in this process is crucial to the development of students' writing skills. As stated by Carson \& Nelson (1996), Miao, Badger, \& Zhen (2006), Rollinson (2005), and Tsui \& Ng (2000), teacher's feedback is important, however, peer feedback should also be equally important. Many researchers have pointed out peer feedback as highly important. Some of the advantages of peer feedback are discussed below:

- Comments or feedback from peers can help develop and enhance a feeling of having an audience. This sense is developed due to having peers as their likely readers who can give comments that would help to enhance the understanding of the produced text; 
- Peer feedback also induces a sense of possession of a text that can also be stated as a customized test with a complete sense of ownership. Another advantage of peer feedback is that it gives students absolute freedom in their taking into consideration of, or rejecting, the presented comments, thus peripherally helping students develop their decision-making skills while refining and elaborating their ideas in the final steps of writing;

- Receiving peer feedback on the linguistic structure and content helps students improve their linguistic competence through learning from others. Peer feedback is generally focused on grammatical errors and inadequately outlined ideas often neglected by writers in the initial stages of the process-based writing. Collaboration helps students to overcome their weaknesses in these areas. It also helps them know their strengths better and acts as a confidence booster for younger writers;

- Receiving verbal peer feedback provides an opportunity for students to elucidate their already existing ideas and helps them to add further aspects to them. It also raises their comprehension level in terms of meanings and structures and helps them discover more practical and effective ways to express their ideas. Consequently, this process leads to the development of critical thinking skills and abilities among young writers and helps them have concerted, collective, and traversable discussions (Hansen \& Liu, 2005);

- Finally, one of the most important issues is that peer feedback helps students understand the fact that teachers' feedback is important but not the only source of authentic consultancy for seeking improvement in their writing process. Peer feedback can actually act as the main driving force to contribute to learner autonomy and a learner-centered learning environment, which is the ultimate aim of collaborative learning for students, especially when developing their writing skills.

Despite the great advantages of peer feedback enumerated so far, there are serious concerns and disadvantages as well (Carson Nelson, 1996; Rollinson, 2005; Tsui \& Ng, 2000). To begin with, the authenticity and reliability of peer feedback can be questionable since it comes from fellow learners and not from native speakers of the English language and they make noticeable errors in their use of the language. Secondly, the notion that teachers' feedback is the only/ultimate authentic source of correction and reference is strongly embedded in learners' mind and they tend to dismiss their fellow students' (peer) feedback as inauthentic. Thirdly, most students are not often competent enough to critically analyze the writing drafts produced by their peers. Another cultural problem is that they tend to avoid criticizing for the fear of hurting their fellow students.

In order to make the most of the process of peer feedback and enhance its positive impact, teachers should try to train their students to engage with each other in the feedback process. They should also help students understand the logic behind peer feedback and teach them how to use this feedback for the development of their writing skills (Storch \& Wigglesworth, 2010). In order to do this, the teacher should offer in-class training in peer feedback as a kind of support system for students and inform them of the advantages of peer review (Berg, 1999; Hansen \& Liu, 2005; Min, 2006). It can help students learn how to give feedbacks and critically analyze the writing drafts of their peers by using the peer review guide. A complete training cycle for peer feedback is a time-consuming process and requires the exertion of great effort, however, in the course of training, teachers can stimulate a positive approach toward peer feedback (O'Brien, 2004). Some peer review activities can be successfully used by teachers to train the students. These activities may include practicing how to clarify the writer's purpose, recognizing the cause of problems, clarifying the types of problems, and putting forward precise propositions for the improvement of the drafts (Min, 2006). The idea of successful acknowledgement and/or rejection of peer feedback depends on students' competence in presenting their comments on their peers' writing drafts. It also depends on students' motivation and willingness to comment on others' drafts and their attitude towards peer feedback. It is therefore imperative to facilitate the implementation of peer review activities since they would definitely help students get trained as good and critical readers.

Besides peer feedback, teacher feedback is equally important and plays a crucial role in the writing process. According to Miao, Badger, \& Zhen (2006), the timing of teacher feedback is very important in the entire process of writing development. Teacher feedback should be scheduled post peer feedback so as to provide students with an opportunity to comment on the drafts from their peers. The mode and frequency of feedback practices could vary from teacher to teacher. According to Ferris (2007), teachers should adopt the right strategy that is an accurate combination of the techniques of right time intervention (the supportive technique) and assumptions (the destructive approach). The aim is to encourage students to work collaboratively towards the production of further drafts. In other words, teachers play a key role in the entire process of incorporating collaboration into the process-based writing because they can help students to focus on the main content of their writing items and also guide students in timely decision-making in the reconstruction of their drafts in their different aspects. 


\subsubsection{The Revision and Editing Stage in the Writing Process}

As in the solo writing process, in the collaborative writing process, students are required to reconstruct their writing samples after the feedback session (the teacher feedback or peer feedback). This stage requires the accurate application of revision and editing techniques. Revising drafts based on the received feedback is an important stage in the process of collaborative writing. On the one hand, revision provides a chance to improve students' drafts. It is, on the other hand, completely dependent on the skills and qualities of the students, i.e. how they skillfully incorporate the feedback points into their drafts and also on the quality of the feedback they receive from their peers (Tsui \& Ng, 2000). The reception of feedback and whether they take it in a constructive manner or otherwise is entirely dependent on the students and their personal attributes. According to Lee and Schallert (2008), the revision stage can include several activities such as reading the text, identifying the glitches, choosing an appropriate approach to implement, and revising the text based on a combination of all of the above. Revision, however, does not simply mean looking for linguistic mistakes. It entails more global issues and the mode of structuring notions in a way that the writer's mindset and viewpoint are made clearer to readers (Widodo, 2006).

According to Shin (2007), editing has a major role in producing the text in a collaborative process-based writing classroom. Editing is in general concerned with basic issues of the writing process such as correcting incorrect spelling or fixing incorrect grammar. It is regarded as the final writing task to be completed by students before the completion of the final draft and after receiving feedback from the peers or the teacher and producing multiple drafts. The main aim of editing is to point out and correct minor grammatical errors and glitches with lexical items and fix the issues with mechanics without interrupting the basic writing flow. Once this step is completed, the final draft is submitted to the teacher for assessment.

\subsection{Assessment Stage as a Post-writing Activity}

After the submission of the final writing draft by students, the assessment phase starts, which is exclusively the teacher's task. There are two approaches used by the majority of teachers depending on institutional obligations or the teachers' personal choices, i.e. the holistic scoring and analytic marking. The holistic approach of assessment is, in general, a loosely defined marking approach. In the holistic assessment approach, a student's writing draft is quickly observed and evaluated against a holistic assessment criteria-based rubric. The writing draft is then rated by the teacher without clearly stating the criteria of the individual writing aspects. The analytical approach of assessment, on the other hand, is focused on a detailed and diagnostic marking method. In the analytical approach, the teacher assesses a student's writing draft based on numerous key points of writing. The main analytical points used in this approach include the content, organization, cohesion, coherence, grammar, vocabulary, and mechanics. According to Sara C. Weigle (2002), the analytical assessment approach allows for a thorough evaluation of a student's writing performance. There have been controversies concerning the two assessment approaches and it is concluded that both scoring systems have advantages and disadvantages. Weigle (2007) believes that the holistic scoring system is faster and more efficient than the analytic scoring system. On the other hand, the analytic scoring system provides more useful feedback to students. In the analytical scoring system, scores of different aspects of writing can be calculated accurately and students can be informed comprehensively on their strengths and weaknesses in their writing skill, Weigle (2007). The selection of either of these assessment systems depends on teachers or institutional obligations such as institutional goals, the class size, time limitation, and the requirements of the writing course assessment. An important point is that teachers should not consider the assessment process as an end in itself but, on the contrary, an ongoing scaffolding process of helping students to improve their writing skills.

After the completion of one entire cycle of collaborative process-based writing activities, students should be encouraged to reflect on the learning points they have achieved within the writing process. Reflecting on the writing process is also a common practice in the solo writing process. It encourages students to self-evaluate and list the strengths and weaknesses they have identified in the course of writing. It also gives them an opportunity to learn from their mistakes and contemplate on how to improve their writing skills. In order to facilitate this reflection process and help students reap even more benefits from this activity, teachers should provide a reflection guide, a rubric or a reflection point sheet to students. From the teachers' perspective, a reflection record helps them to figure out the achievement points of students and prepare a to-do-list so as to be able to provide further guidance to students in their future writing tasks.

\section{Conclusion}

As indicated by Storch (2005), dealing with students' desire and inclination to work solitary is probably the most challenging task for teachers in the process of incorporating the collaborative process-based writing. Therefore, 
it is important that teachers encourage and guide their students to write collaboratively so as to expedite the development of their writing skills. The success and/or failure of collaborative process-based writing depends on various factors such as the teacher's competence in teaching writing skills and how precisely the writing process is managed, the specific writing classroom context, the type of the curriculum and class syllabus devised by the institution, the institutional policy for the assessment method, and the individual qualities of students. The level of language proficiency and writing skills and the motivation to write collaboratively are among the student qualities. In conclusion, writing teachers always need to bear in mind that writing is a joint and collective activity and a time-consuming process, and for students to be competent writers they need to be well aware of their writing goals and work collaboratively towards those goals.

\section{References}

Berg, E. C. (1999). The effects of trained peer response on ESL students' revision types and writing quality. Journal of Second Language Writing, 8(3), 215-241. https://doi.org/10.1016/S1060-3743(99)80115-5

Carson, J. G., \& Nelson, G. L. (1996). Chinese students' perceptions of ESL peer response group interaction. Journal of Second Language Writing, 5(1). 1-19. https://doi.org/10.1016/S1060-3743(96)90012-0

Donato, R. (1994). Collective scaffolding in second language learning. In J. P. Lantolf \& G. Appel (Eds.), Vygotskian approaches to second language research (pp. 33-56). Norwood, NJ: Ablex.

Ferris, D. (2007). Preparing teachers to respond to student writing. Journal of Second Language Writing, 16(3), 165-193. https://doi.org/10.1016/j.jslw.2007.07.003

Gaith, G. M. (2002). The relationship between cooperative learning, the perception of social support, and academic achievement. System, 30(3), 263-273. https://doi.org/10.1016/S0346-251X(02)00014-3

Hammond, J. (Ed.). (2002). Scaffolding teaching and learning in language and literacy education. Newtown, Australia: PETA.

Hansen, J. G., \& Liu, J. (2005). Guiding principles for effective peer response. ELT Journal, 59(1), 31-38. https://doi.org/10.1093/elt/cci004

Harmer, J. (2007). The practice of English language teaching (4th ed.). Essex, England: Pearson Education.

Hyland, K. (2007). Genre pedagogy: language, literacy and 12 writing instruction. Journal of Second Language Writing, 16(3), 148-164. https://doi.org/10.1016/j.jslw.2007.07.005

Jacobs, G. M. (2006). Issues in implementing cooperative learning. In S. G. McCafferty, G. M. Jacobs, \& C. D. Iddings (Eds.), Cooperative learning and second language teaching (pp. 30-46). New York: Cambridge University Press.

Lai, E. R. (2011). Collaboration: a literature review [Research Report]. Retrieved from http://www.pearsonassessments.com/hai/images/tmrs/Collaboration - Review.pdf

Lee, G., \& Schallert, D. L. (2008). Meeting the margins: Effects of the teacher-student relationship on the revision process of EFL college students taking a composition course. Journal of Second Language Writing, 17(3), 165-182. https://doi.org/10.1016/j.jslw.2007.11.002

Miao, Y., Badger, R., \& Zhen, Y. (2006). A comparative study of peer and teacher feedback in a Chinese EFL writing class. Journal of Second Language Writing, 15(3), 179-200. https://doi.org/10.1016/j.jslw.2006.09.004

Min, H. T. (2006). The effects of trained peer review on EFL students' revision types and writing quality. Journal of Second Language Writing, 15(2), 118-141. https://doi.org/10.1016/j.jslw.2006.01.003

Nelson, G. L., \& Murphy, J. M. (1992). An L2 writing group: Task and social dimensions. Journal of Second Language Writing, I(3), 171-193. https://doi.org/10.1016/1060-3743(92)90002-7

O'Brien, T. (2004). Writing in a foreign language: Teaching and learning. Language Teaching, 37(1), 1-28. https://doi.org/10.1017/S0261444804002113

Rao, Z. (2007). Training in brainstorming and developing writing skills. ELT Journal, 61(2), 100-106. https://doi.org/10.1093/elt/ccm002

Rollinson, P. (2005). Using peer feedback in the ESL writing class. ELT Journal, 59(1), 23-30. https://doi.org/10.1093/elt/cci003

Sert, O. (2005). Comparative analysis of pair work and individual assignments in two ELT classes. Journal of Language and Learning, 3(2), 219-232. 
Shin, S. K. (2007). Fire your proofreader! Grammar correction in the writing classroom. ELT Journal, 62(4), 358-365. https://doi.org/10.1093/elt/ccm089

Stapleton, P. (2001). Assessing critical thinking in the writing of Japanese university students: Insights about assumptions and familiarity. Written Communication, 18(4), 506-548. https://doi.org/10.1177/0741088301018004004

Storch, N. (2005). Collaborative writing: Product, process, and students' reflections. Journal of Second Language Writing, 14(3), 153-173. https://doi.org/10.1016/j.jslw.2005.05.002

Storch, N. (2011). Collaborative writing in L2 contexts: Processes, outcomes, and future directions. Annual Review of Applied Linguistics, 31, 275-288. https://doi.org/10.1017/S0267190511000079

Storch, N., \& Wigglesworth, G. (2010). Learners' processing, uptake, and retention of corrective feedback on

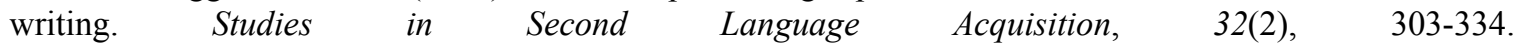
https://doi.org/10.1017/S0272263109990532

Tsui, A. B. M., \& Ng, M. (2000). Do secondary L2 writers benefit from peer comments? Journal of Second Language Writing, 9(2), 147-170. https://doi.org/10.1016/S1060-3743(00)00022-9

Watanabe, Y., \& Swain, M. (2007). Effects of proficiency differences and patterns of pair interaction on second language learning: the collaborative dialogue between adult ESL learners. Language Teaching Research, 11(2), 121-142. https://doi.org/10.1177/136216880607074599

Weigle, S. C. (2002). Assessing writing. Cambridge: Cambridge University Press. https://doi.org/10.1017/CBO9780511732997

Weigle, S. C. (2007). Teaching writing teachers about assessment. Journal of Second Language Writing, 16(3), 194-209. https://doi.org/10.1016/j.jslw.2007.07.004

\section{Copyrights}

Copyright for this article is retained by the author, with first publication rights granted to the journal.

This is an open-access article distributed under the terms and conditions of the Creative Commons Attribution license (http://creativecommons.org/licenses/by/4.0/). 